\title{
Effect of Different CAD/CAM Techniques on Marginal Accuracy, Color Matching and Retention of Cemented versus Screw Retained Implant-supported Crowns.
}

\author{
Latifa F. El-Banna ${ }^{1 *}$, Mohamed A. Al-Yasaky², Hesham A. katamish ${ }^{3}$ and Eman A. Essam ${ }^{4}$
}

Codex : 60/1907

azhardentj@azhar.edu.eg

http://adjg.journals.ekb.eg

DOI: $10.21608 /$ adjg.2019.5480.1019

\section{KEYWORDS}

\section{CAD/CAM Implant}

superstructure;

Veneering techniques; Retention,

Color; Marginal accuracy.

\begin{abstract}
Purpose: Evaluating the effect of different computer aiding designing/computer aiding manufacturing techniques on marginal accuracy, color matching and retention of cemented versus screw retained implant-supported crowns. Materials and Methods: Thirty six zirconia implant supported crowns were constructed and divided according to mode of retention into two groups ( $\mathrm{n}=18$ /group); GpI:Implants supported crowns cement retained to customized zirconia abutments. GpII : Implant-supported crowns screwed directly to implant analogs. Each of the two groups were further subdivided according to mode of veneering into three subgroups(n=6/group).(IA)Full Contoured cement retained zirconia crowns (IB) Solid Zirconia copings veneered by Hand layering \& (IC) Solid Zirconia coping veneered by Heat pressed ingots.(IIA)Full contoured screw retained zirconia crowns (IIB) \& (IIC) Solid Zirconia copings manufactured and veneered as cement retained but they were screwed directly to implant analog. Marginal accuracy, color matching and retention was measured. Results :Press veneered cement retained subgroup(IC)showed the biggest marginal gap value, while full contoured screw retained subgroup(IIA)showed the smallest. Cement retained hand veneered(IB) showed the highest statistically significant color matching acceptance $50 \%$ good, $16.67 \%$ fair,33.3\%adjust).Screw retained group[II] showed statistically significant lower retention mean value than cement retained group[I].The highest statistically significant retention mean value was recorded by press veneered subgroups [C]. Conclusion: Cement retained showed better color matching and resistance to dislodgment than screw retained zirconia CAD/CAM implant supported crowns but the later showed better adaptation. Full contoured showed the lowest marginal gap, hand veneered showed the highest color matching acceptance and press veneered showed the highest retention mean values.
\end{abstract}

- Paper extracted from PhD thesis titled "Effect of Different CAD/CAM Techniques on Marginal accuracy, Color matching and Retention of Cemented versus Screw retained Implant-supported Crowns ".

1. *.Prosthodontist, Al-Zahra University Hospital, Al-Azhar University, Email: 1_elbanna@me.com

2. Professor of Operative Dentistry and Dean of Faculty of Dental Medicine, Sinai University.

3. Professor of Fixed Prosthodontics, Faculty of Oral and Dental Medicine, Cairo University.

4. Professor of Crowns \& Bridges, Faculty of Dental Medicine for Girls , Al-Azhar University. 


\section{INTRODUCTION}

A successful esthetic implant supported restoration for an anterior tooth is one of the most challenging procedure in cosmetic dentistry, requiring a team approach between the surgeon, restorative dentist and laboratory technician. ${ }^{(1)}$ Implant restorations could be screwed to implants directly or they can be cemented to abutments (Cement retained), the choice remains controversial among practitioners ${ }^{(2)}$. When implant is placed in position which lead that the screw access emerges in the esthetic zone, screw retained is not preferred ${ }^{(3)}$. Authors found that no differences between the survival rates of the two types. Screw retained prosthesis showed $83.4 \%$ success in comparison with $93.2 \%$ showed by cement retained, although the results are not significant $(\mathrm{P}>0.05)$. Screw retained protheses show a more accurate fit at the abutment margin, however they show less esthetics appearance ${ }^{(4)}$.Cemented restorations show more simplicity of use, passivity of fit and improved esthetics ${ }^{(5)}$, however removal of cement from subgingival margins has been shown to be unpredictable ${ }^{(6)}$.

The introduction of computer aiding designing /computer aiding manufacturing has facilitated the use of advanced ceramics. Primary design option for such restorations was the fabrication of a framework/coping. Developments in CAD/ CAM have facilitated the design and the processing of monolithic zirconia crowns and fixed partial dentures ${ }^{(7)}$. The interest in using this technology in implant prostheses has been increasing for many reasons; in $\mathrm{CAD} / \mathrm{CAM}$ a solid block of material is used in manufacturing implant frameworks, so it shows high mechanical properties as it is more homogenous, since a lot of laboratory steps are skipped inaccuracies are widely minimized. Also , with this technology the proper emergence profile can be obtained, and implant angulations can be corrected and finally CAD/CAM abutments provide optimal esthetics for the surrounding soft tissues and optimum optical properties of a natural dentition ${ }^{(8)}$.
The use of full contoured zirconia crowns and FDPs was described as a new restoration fabrication option $^{(9)}$. Color characterization was achieved by surface painting only ${ }^{(10)}$ Computer aiding designing/ computer aiding manufacturing had facilitated the performance of veneering ceramics by shaping zirconia abutments according to the contour of the overlaying restoration, which decreases the chance and severity of ceramic chipping. Unfortunately percentage of failure was very high as revealed by studies mentoring the performance of veneered zirconia restorations. Methods to improve veneering of zirconia frameworks ; as press veneering or slowly cooling, are continuously evolving could minimize the risk of fracture of ceramic veneering in the future. Also, milling full contoured restoration with no veneering showed remarkable outcomes ${ }^{(11)}$.

Marginal accuracy is an important criterion in determining the quality and clinical success of a restoration (12). Researchers reported that accuracy of fit of restoration causes diminished microleakage, recurrent caries and periodontal diseases ${ }^{(13)}$. It was found that besides optimal esthetics, an advantage of computer aiding manufacturing/ computer aiding designing generated restorations would be the passive fit of the framework. CAD/CAM systems in general showed comparable or even better results in concern to accuracy of marginal fit ${ }^{(14) .}$ It was found that marginal accuracy plays an important role in influencing the restoration's long-term success ${ }^{(15)}$.

In-vitro studies have showed that marginal misfit of cement implant supported restorations range from 20 to $168 \mu \mathrm{m}^{(16)}$. The measurement recorded in studies for the clinical accepted marginal misfit ranged from 50 to $200 \mu$. Researchers continued to utilize data performed by authors who post experimenting more than 1,000 restorations summarized that $120 \mu \mathrm{m}$ was the maximum accepted marginal discrepancy ${ }^{(17) .}$ In a study done to evaluate the margin fit accuracy of full contoured versus veneered all ceramic restorations, it was found that hand veneered zirconia crowns showed better margin fit compared to those monolithic, lithium disilicate and press veneered lithium disilicate ${ }^{(18)}$ 
In a review study to evaluate the accuracy of fitting of implant copings manufacturing by computer aiding design/computer aiding technique, after searching in PubMed (MEDLINE), fourteen researching were chosen. The techniques preformed to indicate framework accuracy includes : dimensional measurements, microscopic measurement, photogrammetric technique, contact scanner and modelling techniques. The studies used strain gauge analysis in which less strain indicates a better framework fit. They found that misfit exists regardless of the fabrication method and material, however, they also found that computer aiding designing/computer aiding manufacturing technique offers precise marginal fit in comparison with other techniques ${ }^{(19)}$.

Although the aesthetic outcome of implant therapy is important for patients, yet it was not well documented ${ }^{(20)}$ Most shade matching studies that tried to define a range of accepted D E were in vitro studies ${ }^{(21)}$. Acceptable and perceptible colour range shade mismatching was determined in an actual clinical scenario, that 2.6 D E was the range that half the dentist observer could see a colour difference.5.5 D E was the range in which half the dentist choose to remake the restoration due to colour mismatching (22).

Modifications in fabrication and sintering process might improve optical properties of translucent zirconia. Full contoured zirconia restorations have to prove their stability in vitro as veneered zirconia crowns ${ }^{(23)}$. Authors evaluated the role of veneering techniques and aging on the colour reproduction, stability and translucency of translucent zirconia, zirconia coping hand layered by VM9 or press layered by Zirpress. Results showed that regarding color reproduction, DE of translucent zirconia was significantly higher than VM9 and Zirpress. All veneering techniques evaluated in this study were capable of proper color reproduction and any difference whether significant or not was clinically imperceptible ${ }^{(24)}$.

\section{MATERIALS AND METHODS}

Thirty-six implant transfers (analogs) were mounted in epoxy resin blocks. The assemblies were divided according to mode of retention of overlaying implant supported restorations into two main groups $(\mathrm{n}=18$ samples $)$ as follows:

Group (I): In which implant supported assemblies were cement retained to the customized zirconia abutments.

Group (II): In which the implant supported assemblies were screw retained to the implant analogs.

Each of the previous two groups were further subdivided into 3 subgroups ( $\mathrm{n}=6$ samples) according to the technique of CAD/CAM and mode of veneering as follows:

- Subgroup (I A): In which Full contoured Multilayered Supertranslucenct zirconia crowns were cement retained to zirconia abutments.

- Subgroup (I B): In which zirconia copings were hand veneered with feldspathic ceramic then cement retained to zirconia abutments.

- Subgroup $(I C)$ : In which zirconia copings were press veneered with Zirpress ingots then cement retained to zirconia abutments.

- Subgroup (II A): In which Full contoured Multilayered Supertranslucenct zirconia crowns were screw retained to implant analogs.

- Subgroup (II B): In which zirconia copings were hand veneered with feldspathic ceramic then screw retained to implant analogs.

- Subgroup (II C): In which zirconia copings were press veneered with Zirpress ingots then screw retained to implant analogs.

\section{CAD/CAM of Customized Zirconia Abutment}

CAD/CAM of Customized Zirconia Abutment was done by placing scan abutmentonimplant analogs and scanning it. Then matching the scan abutments for detection of implant position on Exocad wizard 
was done.Then detection of emergence profile margin, generating abutment bottoms and verifying the customized design on Exocad software (Fig1). For milling of zirconia abutments, zirconia blank material, serial number, thickness, enlargement factor, number of restorations to be milled and their distributions, along with sprue position were selected on DentalCAM. The zirconia blank was fixed to the milling machine then milling process was activated. Milled zirconia abutments were separated from the blank and sprues attachment points were smoothed. Abutments were ultrasonically cleaned then dried. Coloring of zirconia abutments was accomplished by immersion of the abutments in A2 coloring liquid. Abutments were then sintered for 9 hours in the sintering furnace at $1560^{\circ} \mathrm{c}$. Cementation of customized zirconia abutment to titanium base was accomplished with dual cured resin cement after surface treatment of both abutment and titanium base. (Fig 2)

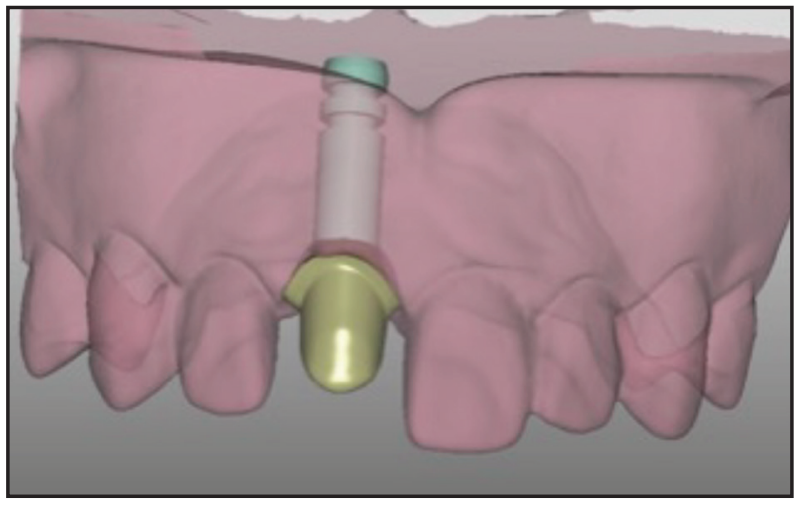

Figure (1) Designed zirconia abutment

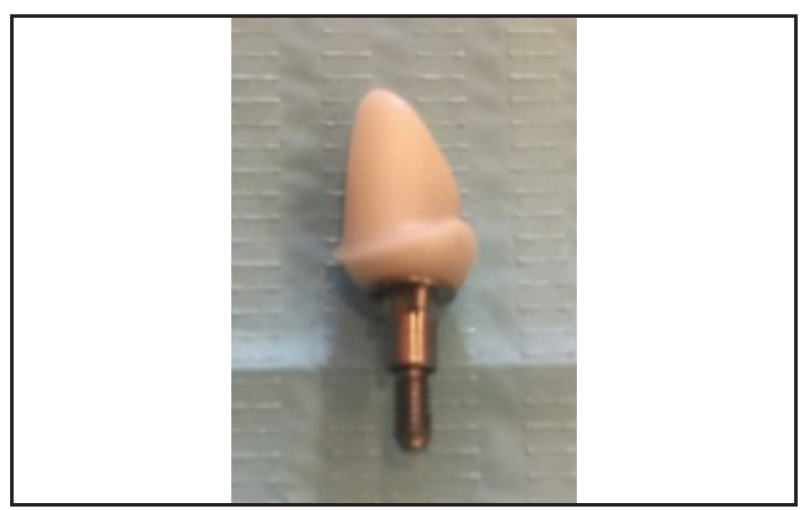

Figure (2) Sintered abutment cemented to titanium base

\section{CAD / CAM of cement retained Full Contoured STML Zirconia Crowns}

After designing the abutment, the crown bottoms which includes; determining the cement gap thickness, the crown borders and dealing with the undercuts then freeform anatomic forming, freeform adjustments and adaptation to adjacent , were designed. The final step was merging. The construction file of the Anatomic crown was forwarded to the manufacturer software (Dental CAM) of the milling machine. The zirconia blank material "KATANA Zirconia Super Translucent Multi Layered", shade A2, thickness " 22 mm", number of restorations to be milled and their distributions along with sprue position and number were selected within the blank. The zirconia blank was fixed to the machine, then milling was activated. The restorations were placed into the refractory sager tray and then in the sintering furnace. A high shine surface was created by polishing, especially on the contact areas then the glaze was applied on all surfaces.Finally, air abrasion of the intaglio interface of zirconia crowns was done with aluminum oxide particles (50 um /2 bar pressure) $5 \mathrm{~cm}$ far, then stored until the time of cementation.

\section{CAD / CAM of cement retained Zirconia Coping Hand Veneered with CZR}

The additive step in this designing wizard was "Shrinking" where we are allowed to reduce the anatomic crown. The Thickness of the coping was changed using minimize thickness tab. The construction file of the coping was forwarded to the manufacturer software (Dental CAM) of the milling machine. The zirconia blank material "bruxzir solid zirconia", thickness "15mm", enlargement factor "1.2277", number of restorations to be milled and their distributions, along with sprue position and number were selected within the blank. The manufacturer process of the cement retained zirconia coping was the same as manufacturing of zirconia abutment. Copings were checked for fitting on the zirconia abutments (Fig. 3). Finally, 
air abrasion of the outer and inner interface of the coping by aluminum oxide (50 um /2 bar pressure) $5 \mathrm{~cm}$ far was done. Application of Body, Enamel and translucent over zirconia coping was performed according to manufacturing instructions. Matching the dimension and form of the designed full contoured tooth was done by the guide of the silicon index in order to recreate the shape precisely.

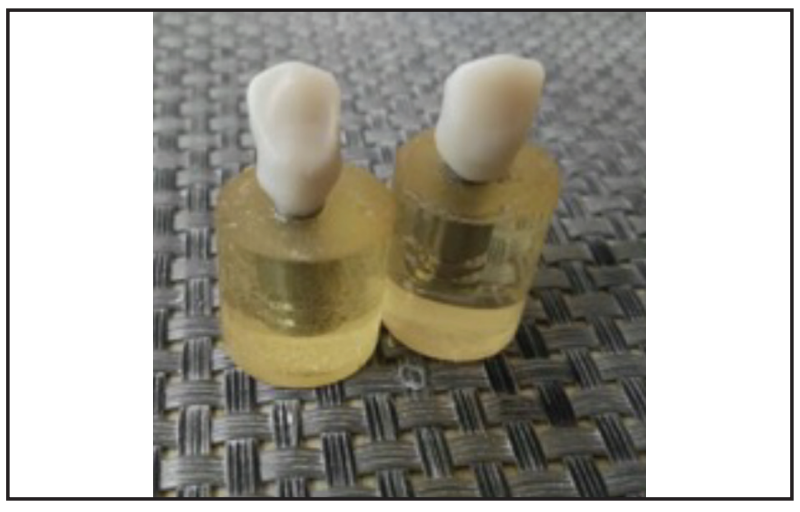

Figure (3) Cement retained Zirconia coping

\section{CAD/CAM of cement retained Zirconia Coping Press Veneered with Zirpress}

Same steps of the previously designing, milling, coloring and sintering of zirconia coping. Application of IPS e.max Ceram ZirLiner before wax-up to assure a strong bond between the framework and the overlaying pressed material. Restoration was designed to full contouring so that it requires only glazing. It was matched to the dimension and form of the designed full contoured tooth by the guide of the silicon index in order to recreate the shape precisely (Fig.4). Then spruing , investing and preheating of the investing ring, but no preheating was done for the IPS e.max Zirpress ingots and Alox plunger. Then the selected press program was started. Divesting after cooling to room temperature (60-90 minutes), followed by using IPS e.max press invex liquid for the removal of the reaction layer, then finishing and glazing.

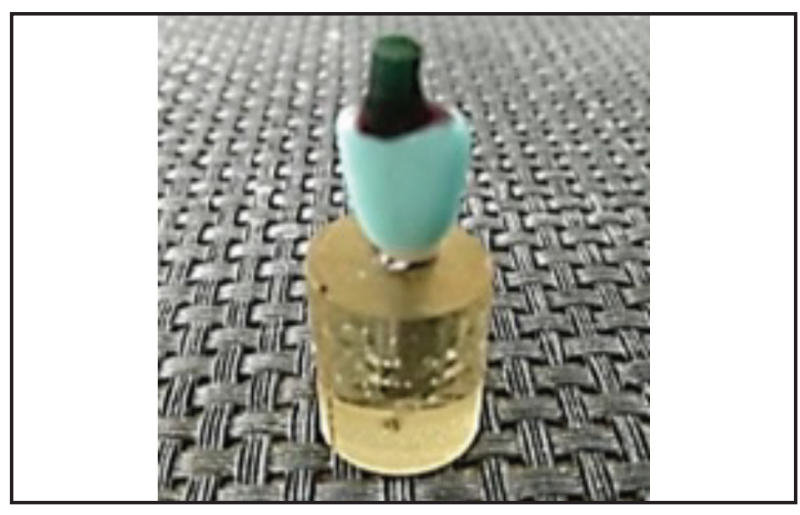

Figure (4) Waxing up and Spruing of press veneered zirconia coping

Cementation of Full contoured zirconia crowns / Hand veneered zirconia crowns / Press veneered zirconia crowns to zirconia abutments

Monobond primer was applied with brush to the sandblasted intaglio surface of the crowns and their corresponding abutments and allowed for natural dry for 20 seconds. The desired quantity of ResiCem was dispensed from the automix syringe directly onto the crowns. The crowns were then seated on their corresponding implant abutment assemblies using finger pressure then $5 \mathrm{~kg}$ load for 5 minutes was applied by using load applicator. Chemical curing started in 30 seconds after restorations were placed and working time was about 3 minutes. Excess material was briefly light cured 1-2 seconds then removed easily with a scaler. Subsequently, all margins were light cured for 40 seconds. The whole specimens were kept in an incubator $37^{\circ} \mathrm{c}$ for 48 hours.

\section{CAD / CAM of Screw Retained Full Contoured STML Zirconia Crowns}

The designing of screw retained restorations was started by matching the scan abutments of implant level scan for restorations direct connected with the implant. Then detection of emergence profile margin, generating crown bottoms, Freeform designing of the crown and screw hole designing then finally merging (Fig 5). Milling process (Fig 6) , sintering, finishing and glazing was done with same 
steps as mentioned previously in manufacturing the full contoured cement retained zirconia crowns except that after sintering, these screws retained full contoured crowns were checked for fitting directly on implant analogs.

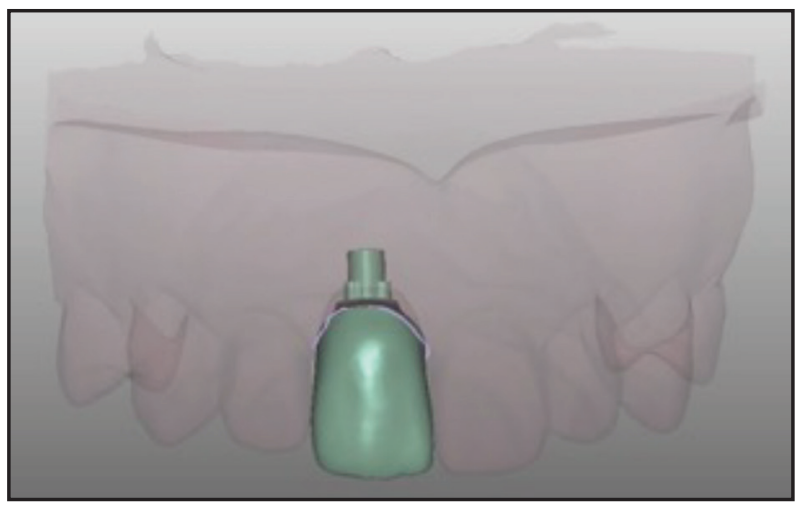

Figure (5) Virtually designed full contour screw retained implant supported crown

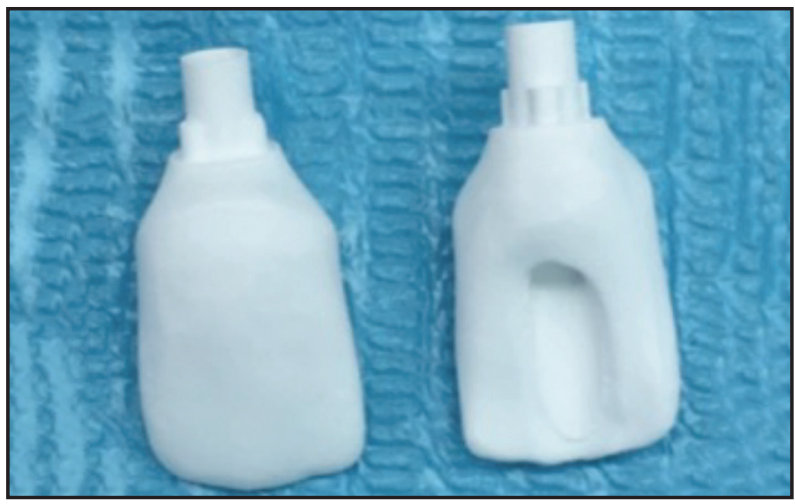

Figure (6) Smoothed presintered full contoured screw retained crowns

\section{CAD/CAM of screw retained Zirconia Coping}

\section{Hand Veneered with CZR}

Same steps of the previously designing, milling, coloring and sintering of cement retained zirconia coping except that it was designed and milled to be fitted directly on implant analogs (Fig.7). Then hand veneering as previously mentioned in cement retained zirconia copings with Cerabien zirconia ceramics except that before sintering of ceramic, the screw cavity was filled at palatal surface with wax to ensure its patency after sintering.

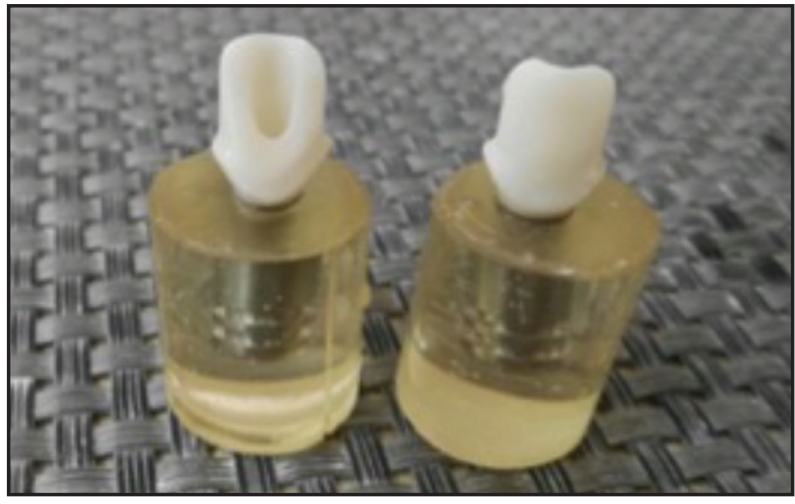

Figure (7) Screw retained zirconia coping

\section{CAD/CAM of screw retained Zirconia Coping Press Veneered with Zirpress}

Same steps as previously mentioned for press veneering of cement retained zirconia copings with IPS e.max zirpress ingots but taking into consideration the patency of the screw access hole.

\section{Screwing of Full contoured / Hand veneered / Press veneered zirconia crowns to implant analogs}

The crowns were engaged and screwed to the implant analog with torque wrench not exceeding 35 $\mathrm{N} / \mathrm{cm}$. Overlying the tightened screw by compacted cotton pellets then monobond primer was applied with brush to the intaglio surface of the screw access holes and allowed for natural dry for 20 seconds. Increments of the desired quantity of composite filling with classical shade A2 was applied to the screw access hole using condenser. Subsequently they were light-cured for 40 seconds.

\section{Testing procedures}

\section{Marginal fit test:}

All tested specimens were seated and cemented or screwed to the implant analog assemblies and then photographed using USB Digital microscope with a built-in camera connected with an IBM compatible personal computer using a fixed magnification of $45 \mathrm{X}$. Specimens were held in place 
over their corresponding dies using holding device. Shots of the margins were taken then morphometric measurements were done for each shot.

\section{Color matching test:}

This test was preformed using the new 5th generation VITA Easy shade V. After selecting the target shade A2, we measured the extent of the match to the target shade which was qualitatively symbolized by red /yellow / green. RED means "Adjust",this means that there is a recognizable difference between the base shade of the restoration and the target shade it was compared to. YELLOW means "Fair", this means that there is a recognizable but still acceptable difference between the base shade of the restoration and the target shade it was compared to. GREEN means "Good", this means that there is little or no difference between the base shade of the restoration and the target shade with which it was compared. To obtain extended shade information, we touched the colored bar. The bars represent the shade intervals numerically and graphically, where $\Delta \mathrm{E}$ is the overall shade deviation of the restoration.

\section{Retention test:}

Retention was measured by retention testing machine with a load cell of $5 \mathrm{kN}$. The upper plate of the machine included specially designed retention measuring device that grasp the acrylic resin embedded suprastructure, which were constructed using cylindrical shaped split copper ring $(20 \mathrm{~mm}$ length and $20 \mathrm{~mm}$ diameter), while the lower compartment holds the epoxy blocks with embedded implant analogs (Fig. 8). The device was subjected to a slowly increasing vertical load $(1 \mathrm{~mm} / \mathrm{min})$ until total dislodgment of the suprastructure assemblies accompanied by decline in load displacement curve recorded by Bluehill Lite software.

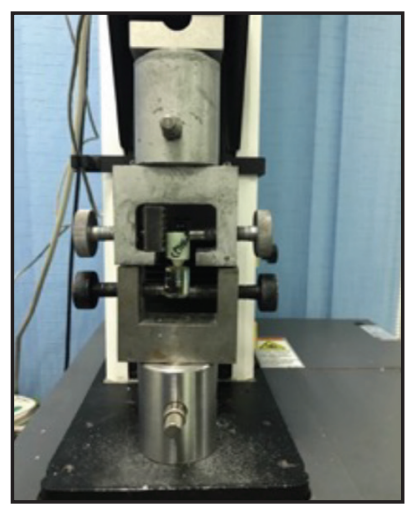

Figure (8) Holding the sample in the retention testing machine

\section{RESULTS}

Results were collected, statistically analyzed and tabulated.

\section{I- Marginal gap:}

Marginal gap results revealed that, full contoured screwed subgroup (IIA) recorded the smallest marginal gap, while press veneered cemented subgroup (IC) recorded biggest marginal gap. Cement retained group [I] showed higher significant $(\mathrm{p}=<.0001,0.05)$ marginal gap $(32.62 \pm 3.63 \mu \mathrm{m})$ than Screw retained group[II] $(20.53 \pm 3.95 \mu \mathrm{m})$. In concern to mode of veneering, the highest marginal gap mean value was recorded by press veneered [C] subgroup $(28.90 \pm 3.69 \mu \mathrm{m})$, followed by hand veneered [B] $(28.19 \pm 4.34 \mu \mathrm{m})$, while the lowest marginal gap mean value was recorded for Full contoured [A] subgroup $(22.63 \pm 3.34 \mu \mathrm{m})$. (Table1\& Figure 9) 
Table (1): Comparison of marginal gap between both retention mode groups with different veneer types

\begin{tabular}{|c|c|c|c|c|c|c|}
\hline \multirow{2}{*}{\multicolumn{2}{|c|}{ Variables }} & \multicolumn{2}{|c|}{ Cement retained (I) } & \multicolumn{2}{|c|}{ Screw retained $(I I)$} & \multirow{3}{*}{$\begin{array}{c}\text { t-test } \\
\text { P value } \\
<.0001 *\end{array}$} \\
\hline & & Mean & $S D$ & Mean & $S D$ & \\
\hline \multirow{3}{*}{ Veneer type } & Full contoured $(A)$ & $28.81^{\mathrm{B}}$ & 4.44 & $16.45^{\mathrm{C}}$ & 3.08 & \\
\hline & Hand veneered $(B)$ & $34.11^{\mathrm{A}}$ & 3.19 & $22.29^{\mathrm{D}}$ & 5.84 & $0.0012 *$ \\
\hline & Press veneered $(C)$ & $34.95^{\mathrm{A}}$ & 5.64 & $22.86^{\mathrm{D}}$ & 2.93 & $0.0002 *$ \\
\hline ANOVA & Pvalue & \multicolumn{2}{|c|}{$0.0232 *$} & \multicolumn{2}{|c|}{$0.0326^{*}$} & \\
\hline
\end{tabular}

Different letter in the same column indicating statistically significant difference $(p<0.05)$

*; significant $(p<0.05)$ ns; non-significant $(p>0.05)$

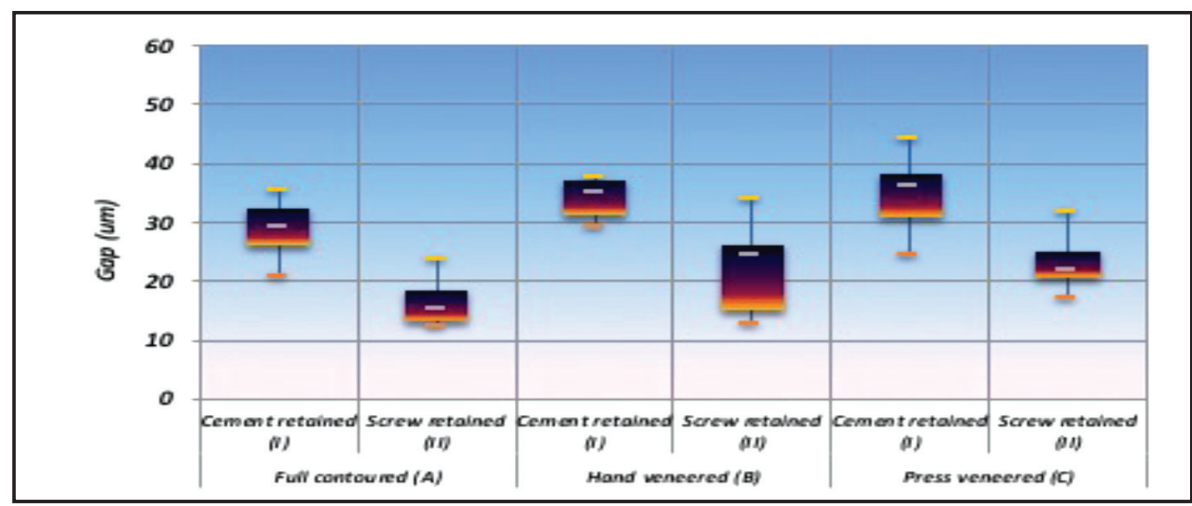

Figure (9) Box plot comparing marginal gap mean values between both groups with different veneer types

\section{II-Color results:}

Quantitative color results revealed that within all studied subgroups, hand veneered cement retained (3.73 $\Delta \mathrm{E})$ and press veneered cement retained
(4.88 $\Delta \mathrm{E})$ subgroup, recorded the only clinically accepted color difference even though they were still considered perceptible. (Table $2 \&$ Figure 10).

Table (2): Comparison of color change ( $\Delta E)$ results (Mean values $\pm S D$ s) between both retention mode groups with different veneer types

\begin{tabular}{|c|c|c|c|c|c|c|}
\hline \multirow{2}{*}{\multicolumn{2}{|c|}{ Variables }} & \multicolumn{2}{|c|}{ Cement retained (I) } & \multicolumn{2}{|c|}{ Screw retained (II) } & \multirow{3}{*}{$\begin{array}{c}\boldsymbol{t} \text {-test } \\
\boldsymbol{P} \text { value } \\
0.4015 \mathrm{~ns}\end{array}$} \\
\hline & & Mean & $S D$ & Mean & $S D$ & \\
\hline \multirow{3}{*}{ Veneer type } & Full contoured (A) & $9.57 \mathrm{~A}$ & 2.2 & $7.6 \mathrm{~A}$ & 1 & \\
\hline & Hand veneered (B) & $3.73 \mathrm{~B}$ & 1.8 & $7.68 \mathrm{~A}$ & 1.65 & $0.005^{*}$ \\
\hline & Press veneered $(C)$ & $4.88 \mathrm{~B}$ & 1.3 & $6.23 \mathrm{~A}$ & 1.7 & $0.2030 \mathrm{~ns}$ \\
\hline ANOVA & Pvalue & \multicolumn{2}{|c|}{$0.0238^{*}$} & \multicolumn{2}{|c|}{$0.3007 \mathrm{~ns}$} & \\
\hline
\end{tabular}

Different letter in the same column indicating statistically significant difference $(p<0.05)$

*; significant $(p<0.05)$ ns; non-significant $(p>0.05)$ 


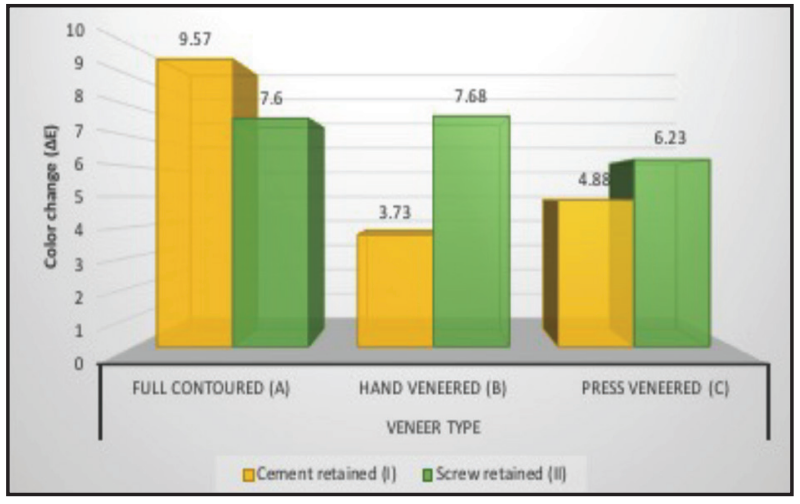

Figure (10) Column chart comparing color change mean values between both groups with different veneer types
While qualitative color results revealed that within all studied subgroups, cement retained hand veneered showed the statistically significant highest color matching acceptance (50\% good, $16.67 \%$ fair, $33.3 \%$ adjust). Cement retained group recorded higher statistically significant color matching acceptance (16.66 \% good,33.33\% fair, $50 \%$ adjust) than screw retained group (0\%good, $16.66 \%$ fair, $83.33 \%$ adjust) (Table3 \& Figure 11).

Table (3): Frequent distribution of color matching score results (\%) for both retention mode groups as function of veneer types

\begin{tabular}{|c|c|c|c|c|c|c|}
\hline \multirow{2}{*}{\multicolumn{2}{|c|}{ Variables }} & \multirow{3}{*}{$\begin{array}{c}\text { Good } \\
0(0 \%)\end{array}$} & \multirow{3}{*}{$\begin{array}{c}\text { Fair } \\
2(33.3 \%)\end{array}$} & \multirow{3}{*}{$\begin{array}{c}\text { Adjust } \\
4(66.67 \%)\end{array}$} & \multicolumn{2}{|c|}{ Chi square } \\
\hline & & & & & Chi & P value \\
\hline \multirow{3}{*}{ Cement retained (I) } & Full contoured (A) & & & & \multirow{6}{*}{332.5} & \multirow{6}{*}{$<.0001 *$} \\
\hline & Hand veneered (B) & $3(50 \%)$ & $1(16.67 \%)$ & $2(33.3 \%)$ & & \\
\hline & Press veneered (C) & $0(0 \%)$ & $3(50 \%)$ & $3(50 \%)$ & & \\
\hline \multirow{3}{*}{ Screw retained (II) } & Full contoured (A) & $0(0 \%)$ & $0(0 \%)$ & $6(100 \%)$ & & \\
\hline & Hand veneered (B) & $0(0 \%)$ & $0(0 \%)$ & $6(100 \%)$ & & \\
\hline & Press veneered (C) & $0(0 \%)$ & $3(50 \%)$ & $3(50 \%)$ & & \\
\hline
\end{tabular}

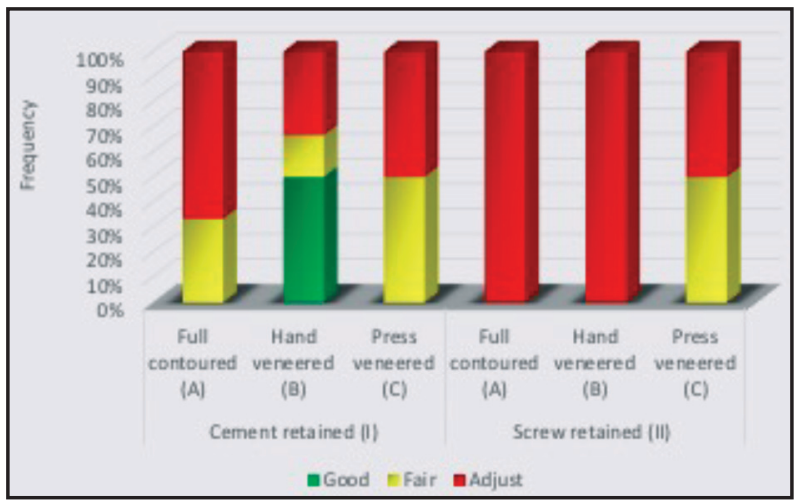

Figure (11) Stacked column chart of color matching score results (\%) for both retention mode groups as function of veneer type

\section{III) Retention:}

Regardless to veneer type totally, it was found that Screw retained showed lower retention mean value cemented. Irrespective of retention mode totally, it was found that the highest statistically significant retention mean value was recorded by Press veneered subgroup (446.445 N), followed by hand veneered subgroup $(359.025 \mathrm{~N})$, then full contoured subgroup (353.375N) (Table 4 \& Figure 12). 
Table (4): Comparison of retention results (Mean values $\pm S D s$ ) between both retention mode groups with different veneer

\begin{tabular}{|c|c|c|c|c|c|c|}
\hline \multirow{2}{*}{\multicolumn{2}{|c|}{ Variables }} & \multicolumn{2}{c|}{ Cement retained (I) } & \multicolumn{2}{c|}{ Screw retained (II) } & t-test \\
\cline { 3 - 8 } & Mean & SD & Mean & SD & P value \\
\hline \multirow{3}{*}{\begin{tabular}{c} 
Veneer type \\
\cline { 2 - 8 }
\end{tabular}} & Full contoured (A) & $453.36^{\mathrm{AB}}$ & 44.68 & $253.39^{\mathrm{C}}$ & 57.74 & $.0005^{*}$ \\
\cline { 2 - 8 } & Hand veneered (B) & $542.05^{\mathrm{A}}$ & 30.87 & $176.00^{\mathrm{D}}$ & 7.46 & $<0.0001^{*}$ \\
\cline { 2 - 8 } & Press veneered (C) & $380.76^{\mathrm{B}}$ & 66.56 & $512.13^{\mathrm{E}}$ & 17.25 & $0.004^{*}$ \\
\hline ANOVA & P value & \multicolumn{2}{|c|}{$0.002^{*}$} & $<0.0001^{*}$ & \\
\hline
\end{tabular}

Different letter in the same column indicating statistically significant difference $(p<0.05)$

*; significant $(p<0.05)$ ns; non-significant $(p>0.05)$

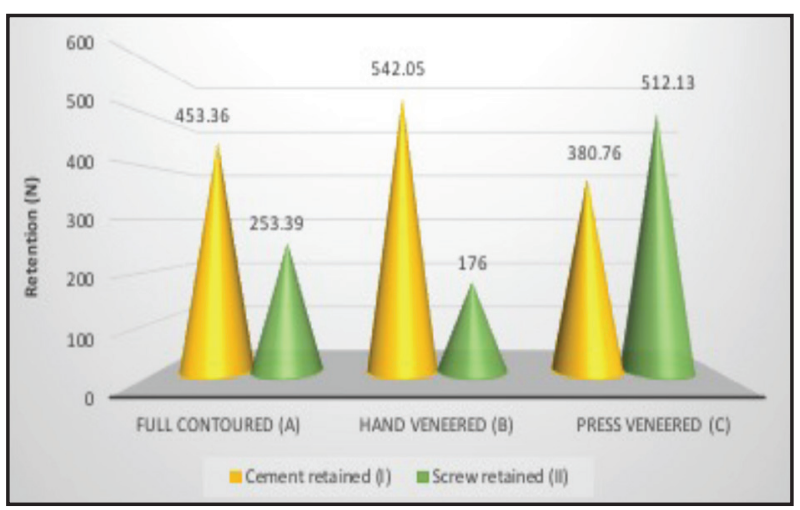

Figure (12) Column chart comparing retention mean values between both groups with different veneer types

\section{DISCUSSION}

To date, there is still little scientific facts in concern to the connection systems of implant supported crowns, and the choice between different types is till confusing (25,26). Although dentist preferred to use the cemented type of implant supported protheses, but patients did not show any favorability ${ }^{(27) \cdot A}$ good rule is that a layered ceramic is typically weaker than a monolithic but potentially have higher esthetic results ${ }^{(28)}$.Lithium disilicate possess the optimum esthetical properties ; toughened zirconia possesses the optimum mechanical properties and cubic zirconia possess a potential compromise ${ }^{(10)}$.
Although various protocols were suggested to measure marginal accuracy, there are no guidelines exist on the ways to be used in marginal gap measurements. For analyzing marginal fit of restorations, two significant internal and external precise types are present.Being noninvasive is considered an advantage for the using of direct viewing in external measurements ${ }^{(29)}$.The approach applied to assess restoration fit in this study was microscopic measurement which can perform quantification measurement for the accuracy of fit of the restorations ${ }^{(19)}$.

In the current study, marginal gap results of all tested samples were within the clinically accepted level. This could be attributed to the minimal human intervention ${ }^{(30)}$. That's why the fitting accuracy of implant borne CAD/ CAM zirconia reconstructions were found to be significantly higher than the conventionally produced bridges with cast alloys ${ }^{(8,19)}$. Although this could be antagonized by others who showed that computer aiding design / computer aiding manufacturing systems have limitations that may affect the integrity of the marginal fit ${ }^{(31)}$. In the current study, Screw retained group [II] recorded statistically significant lower marginal gap mean value than Cement retained group [I]. These results are in agreement with study which stated that any cement margin is inferior to the interface of machined components ${ }^{(32)}$. 
In this study, our results showed that the highest marginal gap mean value was recorded by Press veneered $[\mathrm{C}]$, followed by Hand veneered $[\mathrm{B}]$, while lowest marginal gap mean value was recorded for Full contoured [A]. The difference between subgroups was statistically significant. While no significance was found between Hand veneered (B) and Press veneered (C) subgroups.There is less information comparing the quality of fit of ceramic veneered zirconia with full contoured zirconia restorations ${ }^{(33)}$. These results come in agreement with studies who evaluated changes in marginal accuracy due to the veneering and concluded that veneering did affect the marginal fit of veneered zirconia protheses ${ }^{(17,34)}$. In contrary, these results come in disagreement with authors who found that manually veneered zirconia crowns demonstrated more accurate marginal accuracy compared to those of monolithic and press veneered lithium disilicate ${ }^{(18)}$.

There are several shade matching devices all using different technologies; spectrophotometry, colorimetry and digital imaging ${ }^{(35)}$. In the current study, the latest version of a spectrophotometerbased technology (VITA Easy shade V) was used in color matching. Vita Easy shade is proved to be a reliable and accurate tool in shade selection and matching ${ }^{(36)}$.While much work has been carried over the previous years to assess digital shade selection and matching, not enough information has been reported concerning their application into clinical practice. Delta $\mathrm{E}(\Delta \mathrm{E})$ is a colorimetric measurement that delineates the difference between two colors ${ }^{(37)}$. DE value of 3.3 has been used as the cut off limit of perceptibility in several studies ${ }^{(38)}$. DE values below 3.0 are considered "imperceptible". DE values between 3.0 to 5.0 are considered “ acceptable" and DE values above 5.0 are considered " unacceptable" (39). In the current study samples with good color matching qualities were considered accepted with no or minor modification done by dentist, while samples with fair or adjust color matching qualities were considered unaccepted with much more modification or remake needed to be done by the laboratory ${ }^{(36)}$.

In the current study, within all tested samples our qualitative color matching results revealed that cement retained hand veneered showed the highest color matching acceptance and that cement retained group recorded higher statistically significant color matching acceptance than screw retained. These results agreed with studies recommended the use of cement retained prostheses for esthetic demands ${ }^{(40) \text {. }}$

In the current study, within all studied groups hand veneered cement retained and press veneered cement retained subgroups, recorded the only clinically accepted color difference even though they are still considered perceptible. These results agreed with a study revealed that over $60 \%$ of single tooth implant crowns cases showed a color mismatch between the implant restoration and the natural dentition. This could be considered a serious drawback of implant prostheses in the aesthetic zone ${ }^{(20)}$.

In the current study, the high color difference and low matching acceptance recorded by monolithic full contoured zirconia could be attributed to that full contoured prostheses didn't had adequate translucency due to inconsistency in the refractive index between zirconia particles and the matrix ${ }^{(41)}$. On the other hand, feldspathic and pressable veneering ceramics composed of leucite crystal phase dispersed in feldspathic glassy matrix which simulate the optical properties and colour of natural dentition ${ }^{(42)}$. These results come in agreement with results of study which showed that regarding color reproduction, DE of translucent zirconia milled by full contoured technique was significantly the highest followed by DE of Zirconia coping hand veneered by VM9 low fusing porcelain. The lowest DE was obtained by Zirconia coping veneered by heat pressing (press on technique) ${ }^{(24)}$. These results come in disagreement with study who found that full contoured zirconia crown recorded more light transmission than veneered zirconia framework by 
buildup porcelain and that full contoured zirconia might be considered as an alternative to veneered zirconia ${ }^{(43)}$.

In the current study our results revealed that screw retained group recorded statistically significant lower retentive mean value than cemented group. These results agreed with what was concluded by authors that abutments with zirconia stems, rather than metal stems, are at high risk for fracture, resulting in catastrophic restoration failure ${ }^{(44)}$. In this study results showed that the highest statistically significant retention mean value was recorded by press veneered subgroup followed by hand veneered subgroup and full contoured subgroup. These results may be attributed by what was found by authors who reported that bond strength for pressed samples were higher than for layered samples. They recommended the use pressed ceramics as an alternative to layered in order to reduce the chipping and delamination of ceramics ${ }^{(45)}$.

\section{CONCLUSIONS}

Under the circumstances of this study, the following conclusions could be drawn:

1. Screw retained implant supported zirconia crowns had better marginal adaptation than Cement retained.

2. Full contoured implant supported zirconia crowns had better marginal adaptation than veneered (hand layered or pressed on).

3. Cement retained hand veneered implant supported zirconia crowns showed the highest color matching acceptance within all tested subgroups.

4. Screw retained implant supported zirconia crowns with the three different modes of designing and manufacturing (Full contoured, Hand veneered, Press veneered) didn't record any good color matching quality.
5. Cement retained implant supported zirconia crowns recorded higher retentive mean values than screw retained.

6. Press veneered implant supported zirconia crowns showed higher retentive mean values than full contoured or hand veneered.

\section{Clinical significance:}

Hence, the two implant categories; whether screw or cement retained with the three different manufacturing modes; whether full contoured, hand veneered or press veneered, had variable merits. So, clinicians should make their own decision according to the demands of each clinical situation.

\section{REFERENCES}

1. VreNon P. Dont Gamble in the Anterior Zone.Executing Successful Peri-Implant Esthetics.J Cosmet Dent 2016; 31: 28-37.

2. Shadid R, Sadaqa N. A comparison between Screw and Cement retained Implant Prostheses. A Literature Review. J Oral implant 2012; 38: 298 - 307.

3. Bashutski J, Wang H. Common implant esthetic complications. Implant Dent 2007; 16: 340-348.

4. Weber H, Sukotjo C. Does the type of implant prosthesis affect outcomes in the partially edentulous patient? Int $\mathrm{J}$ Oral Maxillofac Implants 2007; 22:140-172.

5. Chee W, Duncan J, Afshar M, Moshaverinia A. Evaluation of the amount of excess cement around the margins of cement retained dental implant restorations: the effect of the cement application method. J Prosthet Dent 2013; 109: $216-221$

6. DaRocha P, Freitas M and Cunha T. Influence of screw access on the retention of cement retained implant prosthesis. J Prosthet Dent 2013: 109: 264-268.

7. Raigrodski A. Managing prosthetic challenges with a CAD/CAM zirconia restorations. J Cosmet Dent 2014; $30: 40-52$

8. Kapos T, Ashy L, Gallucci G, Weber H, Wismeijer D. Computer aided design and computer assisted manufacturing in prosthetic implant dentisty. Int J Oral Maxillofac Oral Implants 2009; 24 (suppl): 110-117.

9. Marchack B, Futatsuki Y, Marchack C, White S. Customization of milled zirconia copings for all ceramic crowns: a clinical report. J Prosthet Dent 2008; 99: 169-173. 
10. JungY,LeeJ,choiY,AhnJ,ShinS,HuhJ.Astudyonthein vitro wear of the natural tooth structure by opposing zirconia or dental porcelain. J Adv Prosthodont 2010; 2: 111-115.

11. Kohal R, Wolkewitz M, Mueller C.Alumina reinforced zirconia implants: survival rate and fracture strength in a masticatory simulation trial. Clinical Oral Implants Research 2010; 21:1345-1352.

12. Knoernschild K, Campbell S. Periodontal tissue responses after insertion of artificial crowns and fixed partial dentures. J Prosthet Dent 2000; 84: 492-498.

13. Poticny DJ, Klim J. CAD/CAMin-office technology: Innovations after 25 years for predictable, esthetic outcomes, J Amer Dent Assoc 2010; 141: 5S-9S.

14. McLarenE,TerryD.CAD/CAMsystems, materials, andclini cal guidelines for all ceramic crowns and fixed partial dentures. Compend Contin Educ Dent 2002; 23: 637 - 641.

15. Tomita S, Shin-Ya A, Gomi H, Matsuda T, Katagiri S, Suzuki H, Yara A, Ogura H, Hotta Y, Miyazaki T, Sakamoto Y. Machining accuracy of CAD/CAM ceramic crows fabricated with repeated machining using the same diamond bur. Dent Mater J 2005; 24: 123-133.

16. Conrad H, Seong W, Pesun I. Current ceramic materials and systems with clinical recommendations: A systematic review. J Prosthet Dent 2007; 98: 389-404.

17. Kohorst P, Brikmann H, Dittmer M, Borchers L, Stiesch M. Influence of the veneering process on the marginal fit of zirconia fixed dental prosthesis. J Oral Rehabil 2010; 37: 283-291.

18. Martinez-Rus F, Ferreiroa A, Ozscan M, Pradies G. Marginal discrepancy of monolithic and veneered all ceramic crowns on titanium and zirconia implant abutments before and after adhesive cementation: A scanning electron microscopy analysis. Int J Oral Maxillofac Implants 2013; 28: 480-487.

19. Abdou J. Fit of CAD/CAM implant frameworks: A comprehensive review. J Oral implant 2014;40: 758- 766.

20. Happe A, Mattler V, Fickl S, Naumann M, Zoller J, Rothamel D. Spectrophotometric assessment of periimplant mucosa after restoration with zirconia abutments veneered with fluorescent ceramic: a controlled, retrospective clinical study. Clin Oral Impl Res 2011; 0: 1-6.

21. Im S, Torosian A, Blasi A, Londono J, Elkattah R, Chiche G.The challenge of shade matching: How to Achieve more Predictable Outcomes with All-Ceramic Restorations. Biomed J Sci \& Tech Res 2017; 33:64-81.
22. Douglas RD Steingauer TJ,Wee AG. Intraoral determination of the tolerance of dentists for perceptibility and acceptability of shade mismatch. J prosthetic Dent 2007; 97: 200-208.

23. Augstin-Panadero R, Fons -Font A, Roman-Rodriguez J, Granell-Ruiz M, Del Rio-Hichsmith J, Sola-Ruiz M. Zirconia versus metal: a preliminary comparative analysis of ceramic veneer behavior. Int $\mathrm{J}$ prosthodont 2012; 25: 294-300.

24. El-Etreby A, Ebeid A. Effect of low thermal degradation and veneering techniques on color and translucency of Zirconia restorations. EDJ 2015; 61:1-12.

25. Nissan J, Narobai D, Gross O, Ghelfan O, Chaushu G. Long Term Outcome of Cemented Versus Screw Retained Implant Supported Partial Restorations. Int J Oral Maxillofac Implants 2011; 26:1102-1107.

26. Taylor TD, Agar JR, Vogiatzi T. Implant Prothodonics: Current perspectives and future directions. Int Oral Maxillofac Implants 2000; 15: 66-75.

27. Weber H, Kim D, Ng M, Hwang J, Fiorellini J. Perimplant soft tissue health surrounding cement and screw retained implant restorations: a multicenter, 3 years prospective study. Clin Oral Implants Res 2006; 17: 375-395

28. Zarone F, Russo S, Sorrentino R.From porcelain fused to metal to zirconia: clinical and experimental considerations. Dent Mater 2011; 27:83-96

29. Luthardt R, Bornemann G, lemelson S, Walter M, Huls A. An innovative method for evaluation of the 3-D internal fit of CAD/CAM crowns fabricated after direct optical versus indirect laser scan digitizing.Int J Prosthodont 2004; 17:680-685.

30. Takahashi T, Gunne J.Fit of implant frameworks: An in vitro comparison between two fabrication techniques. J Prosthet Dent 2003; 89: 256-260.

31. Reich S, Wichmann M, Nkeneke E, Prosechel P. Cinical fit of all ceramic three unit fixed partial dentures, generated with three different CAD/CAM systems. Eur J Oral Sci 2005; 113:174-179.

32. Chee W, Jivarj S. Screw versus cemented implant supported restorations. Br Dent J 2006; 201: 501-507.

33. Karatasli O, Kursoglu P, Capa N, Kazazoglu E. Comparison of the marginal fit of different coping materials and design produced by computer aided manufacturing systems. Dent Mater J 2011; 30: 97-102. 
34. Park H, Han J, Lee J, Kim S, Yang J. Influence of porcelain veneering on the marginal fit of digident and lava CAD/ CAM zirconia ceramic crowns. J Adv Prosthodont 2010; 2: 33-38.

35. Feuerstein P. A look at shade matching technology. Dentistry IQ. 2003.

36. Dougals R, Brewer J. Variability of porcelain color reproduction by commercial laboratories, J Prosthetic Dent 2003;90: 339-346.

37. Chu S. Precision shade technology: Contemporary strategies in shade selection. Pract Proced Aesthetic Dent 2002; 14: 79-83

38. Kurt M, Ural C, Kulunk T, Sanal A, Erkocak A.The effect of screw color and technique to fill access hole on the final color of screw retained Implant crowns. J Oral Implant 2011; 37:673-679

39. Liu M, Aquilino S, Lund P,Vargas M, Diaz-Arnold A,Gratton D, Qian F. Human perception of dental porcelain translucency correlated to spectrophotometric measurements. J Prosthodont 2010; 19: 187-193.
40. Salinas T, Eckert S. Implant supported single crowns predictably survive to five years with limited complications. J Evid Based Dent Pract 2010; 10: 56-57.

41. Sulaiman TA, Abdulmajeed AA, Donovan TE. Optical properties and light irradiance of monolithic zirconia at variable thicknesses. Dent Mater 2015; 31:1180-1187.

42. Krell A, Klimke J, Hutzler T. Transparent compact ceramics: Inherent physical issues. Opt Mater 2009; 31. $1140-50$

43. Beuera F, Stimmelmayrb M, Guetha J, Edelhoffa D, Naumannc M. In vitro performance of full contour zirconia single crowns. Dent Mater 2012; 28: 449-456.

44. Pette G, Ganeles J, Norkin F. Radiographic appearance of commonly used cements in implant dentistry. Int Periodontics Restorative Dent. 2013; 33: 61-68.

45. Subash M, Vijitha D, Deb S, Satish A, Mahendirakumar N. Evaluation of shear bond strength between zirconia core and ceramic veneers fabricated by pressing and layering techniques: In vitro study. J Pharm Bioallied Sci 2015 Aug;7:S612-615. 